\title{
Post-Discharge Telephonic Follow-Up of Pediatric Patients Affected by SARS-CoV2 Infection: A Safe and Feasible Way to Monitor Children After Hospitalization. The Experience of a Single Italian Pediatric COVID Center.
}

\section{Vitangelo Clemente}

Foundation PVT Polyclinc Tor Vergata: Fondazione PTV Policlinico Tor Vergata

Costanza Tripiciano ( $\square$ costanza.tripiciano@gmail.com )

University of Rome Tor Vergata: Universita degli Studi di Roma Tor Vergata https://orcid.org/00000001-6712-2334

\section{Patrizio Moras}

Foundation PVT Polyclinc Tor Vergata: Fondazione PTV Policlinico Tor Vergata

\section{Daniele Deriu}

Foundation PVT Polyclinc Tor Vergata: Fondazione PTV Policlinico Tor Vergata

Martina Di Giuseppe

Foundation PVT Polyclinc Tor Vergata: Fondazione PTV Policlinico Tor Vergata Annalucia Piscitelli

Foundation PVT Polyclinc Tor Vergata: Fondazione PTV Policlinico Tor Vergata

\section{Michela Cammerata}

Foundation PVT Polyclinc Tor Vergata: Fondazione PTV Policlinico Tor Vergata

\section{Maria Antonietta De loris}

Bambino Gesu Pediatric Hospital: Ospedale Pediatrico Bambino Gesu

Francesca Ippolita Calò Carducci

Bambino Gesu Pediatric Hospital: Ospedale Pediatrico Bambino Gesu

\section{Stefania Bernardi}

Bambino Gesu Pediatric Hospital: Ospedale Pediatrico Bambino Gesu

\section{Andrea Campana}

Bambino Gesu Pediatric Hospital: Ospedale Pediatrico Bambino Gesu

\section{Patrizia D'Argenio}

Ospedale Pediatrico Bambino Gesù: Ospedale Pediatrico Bambino Gesu

\section{Paolo Rossi}

Bambino Gesu Pediatric Hospital: Ospedale Pediatrico Bambino Gesu 
Research

Keywords: Pediatric Patients, Monitor Children, Safe, Feasible

Posted Date: January 18th, 2021

DOI: https://doi.org/10.21203/rs.3.rs-146702/v1

License: (c) (i) This work is licensed under a Creative Commons Attribution 4.0 International License. Read Full License 


\section{Abstract}

\section{Background}

SARS-CoV-2 infection in children is often non severe and in the majority of cases does not require long term hospitalization, nevertheless it is burdened with social issues and managing difficulties. To our knowledge there is no literature on telephonic follow up in pediatric patients with positive PCR for SARSCoV-2 on rhino-pharyngeal swab after discharge. The aim of the study is to describe our experience in a telephonic follow up which can allow early and safe discharge from hospital while keeping the patients under close clinical monitoring.

Materials and Methods

65 children were admitted for SARS-CoV-2 infection at Bambino Gesù Pediatric Hospital COVID Center from 16th March to 3rd July. We monitored through a telephonic follow-up, using a specific survey, the patients discharged still presenting a positive PCR for SARS-CoV-2. We checked if any symptoms occurred at home until recovery, defined as two consecutive negative PCR for SARS-CoV-2 on rhinopharyngeal swabs.

Results

During the follow up 7 patients had mild and self-limited symptoms related to SARS-CoV-2 infection, while 2 patients were re-hospitalized. 1 patient had Multisystem Inflammatory Syndrome in Children (MIS$\mathrm{C})$, the other patient had an increase in troponin and D-dimers. We also monitored the average time of viral shedding, resulting in a median duration of 28 days.

\section{Conclusion}

Our experience describes the daily telephonic follow up as safe in pediatric patients discharged with positive PCR. As a matter of fact it could avoid long term hospitalization and allow to promptly rehospitalize children with major complications such as MIS-C.

\section{Introduction}

In early January 2020 a novel type of Coronavirus (CoV) was identified in a patient affected by pneumonia of unknown origin [1]. The novel coronavirus (2019-nCoV) [2-4] rapidly spread worldwide, forcing the World Health Organization (WHO) to declare the outbreak as a pandemic on 11th March. The disease was named COVID-19 (Coronavirus Disease 2019) $[5,6]$ and the virus SARS-CoV-2 by the International Committee on Virus Taxonomy.

Italy was among the first countries in the world to be affected by the COVID-19 outbreak, with $1.2 \%$ of all patients represented by children [7-13]. According to the Italian Istituto Superiore di Sanità (ISS), the 
estimated overall lethality in Italian patients was $3,4 \%$. Specifically, in pediatric setting the lethality was $0.01 \%$ between the age of 0 and 19 years [14].

Molecular-based approaches are the first line methods to confirm suspected cases of SARS-CoV-2 infection. Nucleic acid testing is the main technique for laboratory diagnosis. Other methods such as virus antigen or serological antibody testing are also valuable assays with a short turnaround time. [15]. The sensitivity and specificity of rhino-pharyngeal swabs for the diagnosis of COVID-19 is not well known. It seems to be very specific, but moderately sensible (with previously published reports citing 63$78 \%$ ), so a negative test does not rule out with confidence the possibility of a SARS-CoV-2 infection. The Real Time-PCR analysis of bronchoalveolar lavage fluid is the most accurate, but it could be performed easily only in patients admitted to a pediatric intensive care unit. The nasal swabs have a higher sensitivity than the pharyngeal. [16]

Based on the global interest and concern about COVID-19 several studies have reviewed symptoms and characteristics of adults with SARS-CoV-2 infection [17]. Given the lower incidence in pediatric patients, there are fewer studies in this cohort. [18-22]

Children mainly acquire SARS-CoV-2 infection from their family members but seem to experience a less severe form of COVID-19 disease than adults. Most of times they are asymptomatic or experience mild symptoms [23]. Frequent clinical manifestations include fever, dry cough and fatigue accompanied by other upper respiratory symptoms, such as nasal congestion and runny nose, pneumonia, dyspnea, headache and arthralgia. Moreover, the main gastrointestinal symptoms are nausea, vomiting and diarrhea. [23] An important complication of the SARS-CoV-2 infection is the Multisystem Inflammatory Syndrome in Children (MIS-C), whose clinical presentation includes fever and involvement of two or more organs, associated with laboratory evidence of inflammation. MIS-C has some similarities with Kawasaki Disease and secondary hemophagocytic lymphohistiocytosis macrophage activation syndrome [24-26].

A previous work has described the potential role of telemedicine in response to public health emergencies [27]. Telemedicine has shown to be helpful in previous outbreaks caused by SARS-CoV (severe acute respiratory syndrome-associated coronavirus) MERS-CoV (Middle East respiratory syndrome coronavirus), Ebola and Zika viruses. Ohanessian R in 2015 proposed a model for telemedicine during public health emergencies, based on tele-expertise, remote patient monitoring of contact cases, and teleconsultation for triage and isolated cases [28]. However in most countries telemedicine is not well integrated with national health care systems. For example in Italy telemedicine was not implemented by health authorities during the first phase of the SARS-CoV-2 epidemic [29]

The aim of this study is to describe our experience with telemedicine, through a telephonic follow-up model, which can allow an early and safe discharge of children with a positive PCR for SARS-CoV-2, while keeping them under close clinical monitoring.

\section{Materials And Methods}


65 children aged between 10 days and 210 months were admitted for SARS-CoV-2 infection, confirmed by positive PCR on rhino-pharyngeal swab, at Bambino Gesù Pediatric Hospital COVID Center, from 16th March to 3rd July. Among these, 19 patients were discharged after remission of symptoms, still presenting a positive PCR on rhino-pharyngeal swab. We monitored through a telephonic follow-up all these 19 patients.

The follow up was performed during working hours by seven residents of the Bambino Gesù Children Hospital, through 2 calls per day to the patients' parents. The calls had a variable length (from 2 to 10 minutes), influenced by numerous variables (e.g., patient conditions, parents' questions, etc.). A specific survey was used (Table 1), in order to check if SARS-CoV-2 - related symptoms appeared [23], if any medication was administrated to the patient and if the rhino-pharyngeal swab was performed. In the case of the appearance of new symptoms, if necessary, the resident gave some management advices (e.g., administration of paracetamol in case of fever). The residents communicated the relevant information obtained from the phone calls to a physician of the Bambino Gesù Children Hospital COVID center.

Table 1

Post-discharge telephonic survey

\section{The resident introduces himself (Full Name, Qualification)}

Which have been the general clinical conditions of the child in the last 12 hours?

Has he had hyperpyrexia in the last 12 hours? If yes, which was his temperature?

Has he had breath difficulties in the last 12 hours?

Has he coughed in the last 12 hours?

Has he had sore throat in the last 12 hours?

Has he had rhinitis in the last 12 hours?

Has he had diarrhea or abdominal pain in the last 12 hours?

Has he had a headache in the last 12 hours?

Has he had arthralgia in the last 12 hours?

Has he manifested other symptoms in the last 12 hours?

Has he had another rhino-pharyngeal swab done? If so, which was the result?

The telephonic follow up was taken forward until two consecutive negative PCR for SARS-CoV-2 were achieved. Two consecutive PCR 24 hours apart were necessary to increase the test senitivity. All the rhinopharyngeal swabs were performed weekly by the local health authority at patients' home.

We tabulated the records through a Microsoft Excel Software, and we used descriptive statistics for the analysis of the data. 


\section{Results}

Our cohort consisted of 19 children aged between 8 and 188 months. Among these, 13 patients were male and 6 female (Table 2). 3 of our patients presented comorbidities: 1 patient was affected by Angelmann syndrome, 1 patient had Congenital Arthrogryposis, 1 patient had Kikuchi Syndrome.

Table 2

Patients according to sex and age

\begin{tabular}{|lllll|}
\hline & $<5$ ys & $\mathbf{5 - 1 2}$ ys & $>12$ ys & Total \\
\hline Total & 5 & 10 & 4 & 19 \\
\hline F & 3 & 1 & 2 & 6 \\
\hline M & 2 & 9 & 2 & 13 \\
\hline
\end{tabular}

At admission the most common symptoms were fever and cough, interstitial lung involvement on chest radiography was observed in 5 patients. 5 of the 19 patients were treated with antibiotics during hospitalization, 1 patient required oxygen therapy. At discharge all patients were asymptomatic.

The average length of hospitalization of our cohort was approximately 10 days, with a range between 5 to 12 days. (Table 3 ) The time of hospitalization was in several cases influenced by non-clinical factors, including familiar and social issues; for example a domicile not adequate for isolation or difficulties of the local health authority in performing rhino-pharyngeal swab to the patients' home.

Table 3

Patients' main features during hospitalization

\begin{tabular}{|lllll|}
\hline & $<\mathbf{5}$ ys & $\mathbf{5 - 1 2}$ ys & $>12$ ys & Total \\
\hline Comorbidity & 0 & 2 & 1 & 3 \\
\hline Asymptomatic & 0 & 3 & 0 & 3 \\
\hline Symptomatic: & 5 & 7 & 4 & 16 \\
$\cdot$ Fever & 3 & 7 & 4 & 14 \\
$\cdot$ Cough & 3 & 2 & 3 & 8 \\
$\cdot$ Other Symptoms & 1 & 8 & 1 & 10 \\
\hline Median days of hospitalization & 10 & 8 & 12 & 10 \\
\hline
\end{tabular}

All the 19 patients were contacted during the follow-up period and 7 of these patients presented new onset symptoms, described in literature as expression of SARS-CoV-2 infection [23], such as sore throat, conjunctivitis, cough, abdominal pain, fever, headache, myalgia and facial rash ( 1 for each child). Most of the symptoms were mild and healed in a few days. 
2 patients were re-hospitalized for complications related to SARS-CoV-2 infection: one patient presented with MIS-C, the other patient had an increase in D-dimers and troponins 28 days after discharge. Both complications were already described in patients with SARS-CoV-2 infection $[26,30]$.

We also monitored the amount of time the PCR for SARS-CoV-2 took to become negative: the median of viral shedding was 28 days, with values between 15 and 59 days.

\section{Discussion}

There is little experience on follow-up in children with SARS-CoV-2 infection [31,32]. Furthermore, to our knowledge there is no literature on the telephonic follow-up in pediatric patients with positive PCR on rhino-pharyngeal swab after discharge.

In our cohort 2 patients were re-hospitalized for the appearance of complications due to SARS-CoV-2 infections.

We compared the average of viral shedding with the data collected by De loris et al and Hongmei Xu et al, and we observed that in our cohort the PCR for SARS-CoV-2 took a longer time to become negative $[33,34]$. Although SARS-CoV-2 infection in the pediatric population is most of the time non severe and often asymptomatic, children's infection is burdened with social issues and management difficulties, due to the need of familial or parental assistance during hospitalization. Early and safe hospital discharge is therefore essential in pediatric patients affected by COVID-19. A telephonic post-discharge follow-up could help to achieve a briefer hospitalization and an early detection of potential complications of the SARS-CoV-2 infection. As a matter of fact we were able to detect at an early stage the patient who presented with MIS-C, which represents a severe complication related to SARS-CoV-2 infection in children, and whose prognosis is influenced by the promptness of treatment [35]

Telehealth could allow to perform a more frequent assess of patients' clinical conditions rather than ambulatorial follow up and could enable a decrease in the number of access to health structures during pandemic phases. Moreover, parents could feel more supervised and reassured through the daily conversation with the doctors of the pediatric COVID center.

In addiction briefer hospitalizations would enable a greater receptivity of the hospital during pandemic phases and would allow to reduce hospitalization related costs as described by Peong Gang Park et al. [31]

The biggest drawback of our study is the limited number of patients. Further studies will be necessary to assess the appropriate timing of calls, based on patients' age and comorbidities.

Our experience highlights the importance of telephonic follow-up in attempting to reduce hospitalization time in SARS-CoV-2 infected patients still presenting a positive PCR on rhino-pharyngeal swab. Finally with this close follow up it would be possible to identify at an early stage late complications related to SARS-CoV-2 infection. 


\section{Abbreviations}

- MIS-C (Multisystem Inflammatory Syndrome in Children)

\section{Declarations}

Funding: Scuola di Pediatria University of Rome Tor Vergata, Academic Department of Pediatrics (DPUO) Bambino Gesù IRCCS Pediatric Hospital

Conflicts of interest/Competing interests: The authors have no conflicts of interest to declare that are relevant to the content of this article.

Ethics approval: The article was approved by the Scientific Department of Bambino Gesù IRCCS Pediatric Hospital, Rome Italy, in view of the retrospective nature of the study and all the procedures being performed were part of the routine care.

Consent to participate N/a

Consent for publication: N/A

Availability of data and material: N/A

Code availability: N/A

\section{References}

1. Li Q, Guan X, Wu P, Wang X, Zhou L, Tong Y, Ren R, Leung KSM, Lau EHY, Wong JY, Xing X, Xiang N, Wu Y, Li C, Chen Q, Li D, Liu T, Zhao J, Liu M, Tu W, Chen C, Jin L, Yang R, Wang Q, Zhou S, Wang R, Liu H, Luo Y, Liu Y, Shao G, Li H, Tao Z, Yang Y, Deng Z, Liu B, Ma Z, Zhang Y, Shi G, Lam TTY, Wu JT, Gao GF, Cowling BJ, Yang B, Leung GM, Feng Z. Early Transmission Dynamics in Wuhan, China, of Novel Coronavirus-Infected Pneumonia. N Engl J Med. 2020 Mar 26;382(13):1199-1207

2. Zhu N, Zhang D, Wang W, Li X, Yang B, Song J, Zhao X, Huang B, Shi W, Lu R, Niu P, Zhan F, Ma X, Wang D, Xu W, Wu G, Gao GF, Tan W; China Novel Coronavirus Investigating and Research Team. A Novel Coronavirus from Patients with Pneumonia in China, 2019. N Engl J Med. 2020 Feb 20;382(8):727-733.

3. Ashour HM, Elkhatib WF, Rahman MM, Elshabrawy HA. Insights into the Recent 2019 Novel Coronavirus (SARS-CoV-2) in Light of Past Human Coronavirus Outbreaks. Pathogens. 2020 Mar 4;9(3):186

4. Coronaviridae Study Group of the International Committee on Taxonomy of Viruses (2020) The species severe acute respiratory syndrome-related coronavirus: classifying 2019-nCoV and naming it SARS-CoV-2. Nat Microbiol 5:536-544 
5. WHO Director-General's opening remarks at the media briefing on COVID-19-11 March 2020. https://www.who.int/dg/

6. Statement on the second meeting of the International Health Regulations (2005) Emergency Committee regarding the outbreak of novel coronavirus (2019-nCoV). https://www.who.int/newsroom/

7. Dong E, Du H, Gardner L. An interactive web-based dashboard to track COVID-19 in real time. Lancet Infect Dis. 2020 May;20(5):533-534.

8. Lu X, Zhang L, Du H, Zhang J, Li YY, Qu J, Zhang W, Wang Y, Bao S, Li Y, Wu C, Liu H, Liu D, Shao J, Peng X, Yang Y, Liu Z, Xiang Y, Zhang F, Silva RM, Pinkerton KE, Shen K, Xiao H, Xu S, Wong GWK; Chinese Pediatric Novel Coronavirus Study Team. SARS-CoV-2 Infection in Children. N Engl J Med. 2020 Apr 23;382(17):1663-1665.

9. Liu W, Zhang Q, Chen J, Xiang R, Song H, Shu S, Chen L, Liang L, Zhou J, You L, Wu P, Zhang B, Lu Y, Xia L, Huang L, Yang Y, Liu F, Semple MG, Cowling BJ, Lan K, Sun Z, Yu H, Liu Y. Detection of Covid19 in Children in Early January 2020 in Wuhan, China. N Engl J Med. 2020 Apr 2;382(14):1370-1371

10. Wu Z, McGoogan JM. Characteristics of and Important Lessons From the Coronavirus Disease 2019 (COVID-19) Outbreak in China: Summary of a Report of 72314 Cases From the Chinese Center for Disease Control and Prevention. JAMA. 2020 Apr 7;323(13):1239-1242

11. Livingston E, Bucher K. Coronavirus Disease 2019 (COVID-19) in Italy. JAMA. 2020 Apr 14;323(14):1335

12. COVID-19 Integrated Surveillance GB-ISS. https://www.iss.it/covid-19-integrated-surveillance. Accessed 30 Mar 2020

13. Dong Y, Mo X, Hu Y, Qi X, Jiang F, Jiang Z, Tong S (2020) Epidemiological characteristics of 2143 pediatric patients with 2019 Coronavirus disease in China. Pediatrics.:e20200702. https://doi.org/10.1542/peds.2020-0702

14. The COVID-19 Task force of the Department of Infectious Diseases and the IT Service Istituto Superio dei Sanità. 22/12/2020 Update

15. Ahn DG, Shin HJ, Kim MH, Lee S, Kim HS, Myoung J, Kim BT, Kim SJ. Current Status of Epidemiology, Diagnosis, Therapeutics, and Vaccines for Novel Coronavirus Disease 2019 (COVID-19). J Microbiol Biotechnol. 2020 Mar 28;30(3):313-324. doi: 10.4014/jmb.2003.03011. PMID: 32238757.

16. Guanmin Jiang, Xiaoshuai Ren, Yan Liu, Hongtao Chen, Wei Liu, Zhaowang Guo, Yaqin Zhang, Chaoqun Chen, Jianhui Zhou, Qiang Xiao, Hong Shan. Application and optimization of RT-PCR in diagnosis of SARS-CoV-2 infection. MedRxiv 2020.02.25.20027755; doi: https://doi.org/10.1101/2020.02.25.20027755

17. Sun K, Chen J, Viboud C. Early epidemiological analysis of the coronavirus disease 2019 outbreak based on crowdsourced data: a population-level observational study. Lancet Digit Health. 2020 Apr;2(4):e201-e208. doi: 10.1016/S2589-7500(20)30026-1. Epub 2020 Feb 20. PMID: 32309796; PMCID: PMC7158945. 
18. Ludvigsson JF. Systematic review of COVID-19 in children shows milder cases and a better prognosis than adults. Acta Paediatr. 2020 Jun;109(6):1088-1095. doi: 10.1111/apa.15270. Epub 2020 Apr 14. PMID: 32202343; PMCID: PMC7228328.

19. Zimmermann P, Curtis N. Coronavirus Infections in Children Including COVID-19: An Overview of the Epidemiology, Clinical Features, Diagnosis, Treatment and Prevention Options in Children. Pediatr Infect Dis J. 2020 May;39(5):355-368

20. She J, Liu L, Liu W. COVID-19 epidemic: Disease characteristics in children. J Med Virol. 2020 Jul;92(7):747-754

21. Shen $K L$, Yang $Y H$, Jiang RM, Wang TY, Zhao DC, Jiang Y, Lu XX, Jin RM, Zheng YJ, Xu BP, Xie ZD, Liu ZS, Li XW, Lin LK, Shang YX, Shu SN, Bai Y, Lu M, Lu G, Deng JK, Luo WJ, Xiong LJ, Liu M, Cui YX, Ye LP, Li JF, Shao JB, Gao LW, Wang YY, Wang XF; China National Clinical Research Center for Respiratory Diseases; National Center for Children's Health, Beijing, China; Group of Respirology, Chinese Pediatric Society, Chinese Medical Association; Chinese Medical Doctor Association Committee on Respirology Pediatrics; China Medicine Education Association Committee on Pediatrics; Chinese Research Hospital Association Committee on Pediatrics; China Non-government Medical Institutions Association Committee on Pediatrics; China Association of Traditional Chinese Medicine, Committee on Children's Health and Medicine Research; China News of Drug Information Association, Committee on Children's Safety Medication; Global Pediatric Pulmonology Alliance. Updated diagnosis, treatment and prevention of COVID-19 in children: experts' consensus statement (condensed version of the second edition). World J Pediatr. 2020 Jun;16(3):232-239

22. Morand A, Fabre A, Minodier P, Boutin A, Vanel N, Bosdure E, Fournier PE. COVID-19 virus and children: What do we know? Arch Pediatr. 2020 Apr;27(3):117-118

23. Castagnoli R, Votto M, Licari A, Brambilla I, Bruno R, Perlini S, Rovida F, Baldanti F, Marseglia GL. Severe Acute Respiratory Syndrome Coronavirus 2 (SARS-CoV-2) Infection in Children and Adolescents: A Systematic Review. JAMA Pediatr. 2020 Sep 1;174(9):882-889

24. Feldstein LR, Rose EB, Horwitz SM, Collins JP, Newhams MM, Son MBF, Newburger JW, Kleinman LC, Heidemann SM, Martin AA, Singh AR, Li S, Tarquinio KM, Jaggi P, Oster ME, Zackai SP, Gillen J, Ratner AJ, Walsh RF, Fitzgerald JC, Keenaghan MA, Alharash H, Doymaz S, Clouser KN, Giuliano JS Jr, Gupta A, Parker RM, Maddux AB, Havalad V, Ramsingh S, Bukulmez H, Bradford TT, Smith LS, Tenforde MW, Carroll CL, Riggs BJ, Gertz SJ, Daube A, Lansell A, Coronado Munoz A, Hobbs CV, Marohn KL, Halasa NB, Patel MM, Randolph AG; Overcoming COVID-19 Investigators; CDC COVID-19 Response Team. Multisystem Inflammatory Syndrome in U.S. Children and Adolescents. N Engl J Med. 2020 Jul 23;383(4):334-346

25. Dufort EM, Koumans EH, Chow EJ, Rosenthal EM, Muse A, Rowlands J, Barranco MA, Maxted AM, Rosenberg ES, Easton D, Udo T, Kumar J, Pulver W, Smith L, Hutton B, Blog D, Zucker H; New York State and Centers for Disease Control and Prevention Multisystem Inflammatory Syndrome in Children Investigation Team. Multisystem Inflammatory Syndrome in Children in New York State. N Engl J Med. 2020 Jul 23;383(4):347-358 
26. Nakra NA, Blumberg DA, Herrera-Guerra A, Lakshminrusimha S. Multi-System Inflammatory Syndrome in Children (MIS-C) Following SARS-CoV-2 Infection: Review of Clinical Presentation, Hypothetical Pathogenesis, and Proposed Management. Children (Basel). 2020 Jul 1;7(7):69

27. Lurie N, Carr BG. The Role of Telehealth in the Medical Response to Disasters. JAMA Intern Med. 2018 Jun 1;178(6):745-746

28. Ohannessian R. Telemedicine: Potential applications in epidemic situations. European Research in Telemedicine/La Recherche Européenne en Télémédecine. 2015 Sep;4(3):95-98.

29. Ohannessian R, Duong TA, Odone A. Global Telemedicine Implementation and Integration Within Health Systems to Fight the COVID-19 Pandemic: A Call to Action. JMIR Public Health Surveill. 2020 Apr 2;6(2):e18810

30. Tersalvi G, Vicenzi M, Calabretta D, Biasco L, Pedrazzini G, Winterton D. Elevated Troponin in Patients With Coronavirus Disease 2019: Possible Mechanisms. J Card Fail. 2020 Jun;26(6):470-475

31. Park PG, Kim CH, Heo Y, Kim TS, Park CW, Kim CH. Out-of-Hospital Cohort Treatment of Coronavirus Disease 2019 Patients with Mild Symptoms in Korea: an Experience from a Single Community Treatment Center. J Korean Med Sci. 2020 Apr 6;35(13):e140

32. Denina M, Pruccoli G, Scolfaro C, Mignone F, Zoppo M, Giraudo I, Silvestro E, Bertolotti L, Rosati S, Ramenghi U, Garazzino S. Sequelae of COVID-19 in Hospitalized Children: A 4-Months Follow-Up. Pediatr Infect Dis J. 2020 Dec;39(12):e458-e459

33. Xu H, Liu E, Xie J, Smyth RL, Zhou Q, Zhao R, Zang N, Long X, Tang Y, Estill J, Yang S, Zhu J, Yan X, Gong F, Tian W, Zhou X, Mo Y, Xiao H, Tang Z, Chen Y, Wang Y, Cui Y, Fang X, Li F, Tian Y, Li P, Deng Q, Ren C, He R, Li Y, Qin H, Wang A, Deng H, Wu J, Meng W, Li W, Zhao Y, Luo Z, Wang Z, Chen Y, Wong GWK, Li Q. A follow-up study of children infected with SARS-CoV-2 from western China. Ann Transl Med. 2020 May;8(10):623

34. De loris MA, Scarselli A, Ciofi Degli Atti ML, Ravà L, Smarrazzo A, Concato C, Romani L, Scrocca R, Geremia C, Carletti M, Calò Carducci FI, Bernardi S, Coltella L, Santilli V, Chiurchiu S, Peschiaroli E, Mariani R, Marabotto C, Perrotta D, Villani A, Rossi P, D'Argenio P, Campana A, Raponi M. Dynamic Viral Severe Acute Respiratory Syndrome Coronavirus 2 RNA Shedding in Children: Preliminary Data and Clinical Consideration from a Italian Regional Center. J Pediatric Infect Dis Soc. 2020 Jul 13;9(3):366-369.

35. Consiglio CR, Cotugno N, Sardh F, Pou C, Amodio D, Rodriguez L, Tan Z, Zicari S, Ruggiero A, Pascucci GR, Santilli V, Campbell T, Bryceson Y, Eriksson D, Wang J, Marchesi A, Lakshmikanth T, Campana A, Villani A, Rossi P; CACTUS Study Team, Landegren N, Palma P, Brodin P. The Immunology of Multisystem Inflammatory Syndrome in Children with COVID-19. Cell. 2020 Nov 12;183(4):968-981 